\title{
PENGARUH KOMPETENSI, KOMITMEN ORGANISASI, PARTISIPASI MASYARAKAT, DAN SISTEM PENGENDALIAN INTERNAL TERHADAP AKUNTABILITAS PENGELOLAAN DANA KAMPUNG DIKOTA JAYAPURA
}

\author{
Cornelia Desiana Matani \\ corrymatani@gmail.com \\ Linda Hutajulu \\ lindahutajulu@gmail.com
}

\begin{abstract}
Abstrak
The objective of this paper is to empirically test the determinants of accountability of village fund management in Jayapura municipality. The factors comprise of the competence of village officials, organizational commitment, community participation and internal control system.

This research is a quantitative study using a survey method. Primary data were collected using a questionnaire distributed to village officials and community respondents in 14 villages in Jayapura municipality. The village apparatus consists of the Head, Secretary, Treasurer, Head of Affairs, village boards, and the communities. The analysis tool used is Warp PLS 6.0.

The research results showed that the competence of village officials, community participation and the internal control system have significant effects on the accountability of village fund management. Organizational Commitment variable has no significant effect. The contribution of this research is that the competence of village officials, community participation and a good internal control system can increase the accountability of village fund management in Jayapura municipality. The government needs to intervene taking the form of assistance activities related to the determinants of this accountability, so that the management of village funds can be improved at Jayapura municipality.
\end{abstract}

Keywords: Village Fund Accountability, Village Apparatus Competence, Organizational Commitment, Community Participation and Internal Control Systems

\section{PENDAHULUAN}

Dana Desa merupakan salah satu bentuk perwujudan pelimpahan kekuasaan pemerintah pusat kepada pemerintah desa. Hal ini dimaksudkan sebagai upaya pemerintah dalam percepatan pembangunan. Pelimpahan kekuasaan juga diiringi dengan transfer dana kepada desa. Dana desa sudah mulai diterima mulai tahun 2015. Pemerintahan presiden Jokowi telah mengeluarkan Rp 187 trilyun dana desa sejak 2015. Pada tahun 2015 berjumlah Rp 20,7 trilyun, tahun 2016 meningkat menjadi Rp 47 trilyun, tahun 2017 menjadi Rp 50 trilyun, tahun 2018 meningkat menjadi Rp 60 trilyun dan dana desa ditahun 2019 naik menjadi Rp 70 trilyun ditambah Rp 3 trilyun Alokasi Dana Desa sehingga menjadi Rp 73 trilyun. Dengan besaran dana ini pemerintah desa diharapkan dapat mempercepat proses pembagunan di desanya melalui pembangunan infrastruktur untuk pendidikan, pelayanan kesehatan, air bersih dan pembagunan jalan desa. 
Pemberian dana desa dipandang serius oleh pemerintah sehingga diatur dalam dalam beberapa aturan pemerintah. Undang-Undang No. 6 tahun 2014 tentang desa, Peraturan Menteri Dalam Negeri No. 113 tahun 2014 yang direvisi menjadi Peraturan Menteri Dalam Negeri No. 20 tahun 2020 tentang pengelolaan keuangan desa serta Peraturan Menteri Desa, Pembangunan Daerah Tertinggal, dan Transmigrasi Nomor 16 Tahun 2018 Tentang Prioritas Penggunaan Dana Desa Tahun 2019. Berbagai aturan ini secara khusus mengatur kewenangan dan penggunaan dana desa sesuai peruntukannnya demi terciptanya desa yang maju, mandiri dan meningkatkan kesejahteraan masyarakat.

Terdapat beberapa fenomena ketidaksesuaian penggunaan dana desa di tahun 2015 berdasarkan hasil laporan evaluasi. Terdapat keterlambatan dan rendahnya penyaluran dana desa dari kabupaten/kota ke desa. Dalam hal penggunaan dana desa, masih terdapat penggunaan dana desa diluar prioritas penggunaan, pekerjaan konstruksi dilakukan seluruhnya oleh pihak ketiga, hasil pengadaan tidak dapat digunakan/dimanfaatkan, pengeluaran dana desa tidak didukung dengan bukti yang memadai, dan kelebihan perhitungan volume RAB (Kementerian Keuangan RI, 2016:19). Hasil evaluasi penggunaan dana desa semester satu tahun 2016 masih mengalami permasalahan. Permasalahan tersebut antara lain: penggunaan dana desa diluar bidang prioritas, pengeluaran dana desa tidak didukung dengan bukti yang memadai, pekerjaan konstruksi dilakukan seluruhnya oleh pihak ketiga/ penyedia jasa, kelebihan pembayaran, pemungutan dan penyetoran pajak tidak sesuai, dana disimpan bukan di RKD, dan pengeluaran diluar APBDesa (Kementerian Keuangan RI, 2016:19).

Dalam meningkatkan kepercayaan publik atas pengelolaan dana desa diperlukan akuntabilitas. Beberapa penelitian terdahulu telah mengidentifikasi faktor-faktor yang mempengaruhi akuntabilitas dana desa. Triyono et. Al (2019) meneliti faktor seperti penyajian laporan keuangan, aksesibilitas laporan keuangan, kualitas pengawasan dari BPD, kapasitas aparat kampung, sistem keuangan desa, dan sistem pengendalian internal terhadap akuntabilitas pengelolaan dana desa. Widyatama et al (2017) mempelajari faktor penentu akuntabilitas pengelolaan dana desa yakni kompetensi dan sistem pengendalian 
internal di Kabupaten Sigi. Mada et al (2017) menganalisis faktor penentu akuntabilitas dana desa di kabupaten Gorontalo yaitu kompetensi aparat pengelola, komitmen organisasi pemerintah desa, dan partisipasi masyarakat berpengaruh positif dan signifikan.

Berdasarkan uraian diatas, maka peneliti tertarik meneliti tentang "Pengaruh Kompetensi Aparat Pengelola, Komitmen Organisasi, Partisipasi Masyarakat dan Sistem Pengendalian Internal terhadap pengelolaan dana desa di Kota Jayapura". Penelitian ini mereplikasi penelitian Mada et al (2017). Perbedaan penelitian ini yaitu objek penelitian dilaksanakan di Kota Jayapura dan menambahkan satu variable penelitian yakni sistem pengendalian internal.

Adapun rumusan permasalan penelitian ini adalah sebagai berikut: (1) Apakah kompetensi aparat pengelola dana desa berpengaruh terhadap akuntabilitas pengelolaan dana desa?; (2) Apakah komitmen organisasi pemerintah desa berpengaruh terhadap akuntabilitas pengelolaan dana desa?; (3) Apakah partisipasi masyarakat berpengaruh terhadap akuntabilitas pengelolaan dana desa?; dan (4) Apakah sistem pengendalian internal berpengaruh terhadap akuntabilitas pengelolaan dana desa?

Penelitian ini mempunyai tujuan sebagai berikut:

1. Memperoleh bukti empiris kompetensi aparat pengelola dana desa berpengaruh terhadap akuntabilitas pengelolaan dana desa

2. Memperoleh bukti empiris komitmen organisasi pemerintah desa berpengaruh terhadap akuntabilitas pengelolaan dana desa

3. Memperoleh bukti empiris partisipasi masyarakat berpengaruh terhadap akuntabilitas pengelolaan dana desa

4. Memperoleh bukti empiris sistem pengendalian internal berpengaruh terhadap akuntabilitas pengelolaan dana desa

Kontribusi penelitian ini memberikan bukti empiris faktor-faktor penguat akuntabilitas pengelolaan dana kampung di 14 kampung di Kota Jayapura sehingga pemerintah yakni OPD teknis terkait dapat merumuskan kegiatan pendampingan yang berkontribusi pada terciptanya akuntabilitas. 


\section{LANDASAN TEORI DAN PENGEMBANGAN HIPOTESIS}

\section{Stewardship Theory}

Penelitian ini menggunakan teori penatalayanan atau Stewarship Theory sebagai grand theory. Teori ini dikemukakan oleh Donaldson dan Davis (1991) bahwa manajer sebagai pengelola atau steward diyakini menjadikan kepentingan bersama sebagai dasar atas tindakannya. Manajer akan menyelaraskan keinginannya dengan keinginan principal dalam mencapai tujuan bersama organisasi meskipun mungkin ada kepentingan steward yang tidak sama. Keterkaitan antara stewardship theory dan penelitian ini yaitu pemerintahan kampung sebagai organisasi publik yang juga mengelola dana kampung dipandang sebagai pengelola yang diharapkan dapat bekerja sesuai dengan kepentingan masyarakat sebagai principal. Aparat kampung diharapkan dapat bekerja dengan baik dalam mencapai tujuan memaksimalkan fungsinya dalam memberikan pelayanan dasar masyarakat kampung.

\section{AKUNTABILITAS}

Akuntabilitas dapat dimaknai sebagai proses pemberiian informasi diatara dua pihak atau lebih yang mana salah satu pihak yang dipercaya sebagai manajemen memberikan pertanggungjelasan atas asset yang dipercayakan kepadanya untuk dikelola (Grey et. al, 1997). Menurut Triyono et. al (2019) akuntabilitas pengelolaan dana kampung merupakan sebuah proses yang dimulai dari perencanaan, pelaksanaan, penatausahaan sampai dengan pelaporan dana kampung yang dipercayakan masyarakat agar dikelola aparat kampung. Widyatama et al. (2017) mengutip pernyataan Jorge et al. (2011) bahwa sumber daya yang dikelola aparat pemerintah perlu dinformasikan kepada masyarakat. Akuntabilitas menjadikan pemerintah dapat dipercaya dan didukung oleh masyarakat sebagai pemilik sumber daya.

\section{KOMPETENSI APARAT}

Airswort, Smith dan Millership (2007:73) dalam Widyatama et. al. (2017) mendefiniskan kompetensi sebagai kombinasi pengetahuan dan keterampilan yang relevan 
dengan pekerjaan. Menurut Apriana et. al. (2020) kompetensi sumber daya manusia merupakan kemampuan melaksanakan tugas dan tanggungjawab yang diberikan dengan standar pendidikan, pelatihan dan pengalaman yang sesuai. Dapat diartikan secara luas kompetensi aparat adalah kemampuan dan pengetahuan yang diperoleh baik melalui pendidikan, pelatihan maupun pengalaman dalam melaksanakan tugas dan tanggungjawab.

\section{KOMITMEN ORGANISASI}

Komitmen organisasi menurut Sumarno (2005) dalam Nurkhasanah (2019) adalah dorongan dari dalam diri individu dalam bertindak demi kepentingan organisasi pemerintahan kampung sehingga tujuan organisasi dapat tercapai. Hal ini menunjukan sejauh mana keberpihakan aparat kampung dalam memihak dan mempertahankan keanggotaan atas pemerintahan kampung demi pencapaian tujuan dan kesesuaian nilai-nilai. Komitmen organisasi terbagi menjadi 2 jenis yaitu komitmen perilaku dan komitmen tingkah laku (Apriana et. al., 2020).

\section{PARTISIPASI MASYARAKAT}

Partisipasi masyarakat merupakan bentuk keikutsertaan dan keterlibatan secara aktif dalam proses pembangunan dan menikmati manfaat pembangunan yang sesuai dengan kebutuhannya. Partisipasi masyarakat dalam pembangunan didesa diamanatkan oleh Undang-Undang Nomor 6 Tahun 2014. Bentuk patisipasi masyarakat dimulai dari proses perencanaan sampai dengan pelaporan atas pengelolaan dana desa/kampung.

\section{SISTEM PENGENDALIAN INTERNAL}

Berdasarkan Peraturan Pemerintah Nomor 60 Tahun 2008 pasal 1 ayat (1) Sistem Pengendalian Internal (SPI) adalah "proses yang integral pada tindakan dan kegiatan yang dilakukan secara terus menerus oleh pimpinan dan seluruh pegawai untuk memberikan keyakinan memadai atas tercapainya tujuan organisasi melalui kegiatan yang efektif dan efisien, keandalan pelaporan keuangan, pengamanan asset negara dan ketaatan terhadap 
peraturan perundang-undangan". Komponen SPI terdiri dari lingkungan pengendalian, penilaian risiko, kegiatan pengendalian, informasi dan komunikasi dan pemantauan pengendalian intern.

\section{PENGEMBANGAN HIPOTESIS}

\section{Pengaruh Kompetensi Aparat terhadap Akuntabilitas}

Kompetensi aparat kampung dalam melaksanakan tugas dan tanggungjawabnya akan meningkatkan akuntabilitas (Mada et. al, 2017). Aparat kampung yang kompeten akan meningkatkan kinerja yang juga sadar akan pentingnya akuntabilitas. Beberapa penelitian terdahulu membuktikan bahwa terdapat pengaruh yang positif dan signifikan antara kompetensi aparat kampung dan akuntabilitas (Mada et. al., 2017; Aziiz \& Prastiti (2019); Umaira \& Adnan, 2019; Hendariz \& Siraz, 2020; Hardiningsih et.al., 2020; Apriana et. al., 2020). Sedangkan beberapa penelitian lain menemukan tidak adanya pengaruh antara kompetensi aparat terhadap akuntabilitas (Widayatama et. at, 2017; Triyono et.al., 2019; Nurkhasanah, 2019). Berdasarkan ketidakkonsistenan hasil pengujian empiris maka dapat dirumuskan hipotesis sebagai berikut:

\section{H1: Kompetensi aparat berpengaruh positif dan signifikan terhadap akuntabilitas dana} kampung.

\section{Pengaruh Komitmen Organisasi terhadap Akuntabilitas}

Komitmen organisasi merupakan kesadaran yang dibangun dalam diri aparat kampung untuk loyal dan mendedikasikan diri kepada pencapaian tujuan organisasi. Adanya komitmen meningkatkan akuntabilitas. Brown dan Moore (2001:20) dalam Mada et. al (2017) menyakini akuntabilitas dapat tercapai dengan adanya komitmen organisasi untuk berusaha dengan maksimal dalam melaksanakan tugas organisasi. Beberapa penelitian tentang pengaruh komitmen organisasi terhadap akuntabilitas masih belum menemukan hasil empiris yang konsisten (Mada et. al, 2017; Nurkhasanah, 2019; Hardiningsih et.al., 2020; Apriana et. al., 2020). Oleh karena itu, hipotesis yang dapat dirumuskan sebagai berikut: 
H2: Komitmen organisasi berpengaruh positif dan signifikan terhadap akuntabilitas dana kampung.

\section{Pengaruh Partisipasi Masyarakat terhadap Akuntabilitas}

Keterlibatan masyarakat melalui partisipasi terhadap tahapan pengelolaan dana kampung juga diyakini meningkatkan akuntabilitas (Mada et. al, 2017). Sujarweni (2015) dalam Nurkhasanah (2019) mendefinisikan partisipasi sebagai prinsip setiap warga desa yang sadar akan haknya untuk terlibat aktif dalam pengambilan keputusan pada program dan kegiatan pemerintah desa. Beberapa penelitian terdahulu juga menemukan adanya pengaruh antara partisipasi masyarakat dengan akuntabilitas (Sugista, 2017; Nurkhasanah 2019, Andriani 2019; Umaira \& Adnan, 2019; dan Astuti, 2019). Sehingga dapat dirumuskan hipotesis penelitian sebagai berikut:

H3: Partisipasi masyarakat berpengaruh positif dan signifikan terhadap akuntabilitas dana kampung.

\section{Pengaruh Sistem Pengendalian Internal terhadap Akuntabilitas}

Keberadaan sistem pengendalian internal yang memadai dilingkungan pemerintahan kampung tidak terlepas dari upaya menciptkan pemerintahan yang mencapai tuujuan dengan efektif dan efisien, menghasilakn pelaporan yang andal dan reliable, kepatuhan terhadap regulasi dan menjaga asset di kampung. SPI diharapkan menjadi sistem yang menciptakan akuntabilitas kampung yang handal dan dapat dipercaya masyarakat. Beberapa studi menemukan bahwa pengendalian internal merupakan salah satu faktor yang mempengaruhi akuntabilitas pengelolaan dana kampung (Widyatama et. al., 2017; Aziiz \& Prastiti 2019; Hardiningsih et. al., 2020; Hendariz \& Siraz, 2020). Sedangkan hasil uji empiris yang dilakukan oleh Triyono et. al. (2019) menunjukan hasil yang berbeda yaitu bahwa sistem pengendalian internal tidak berpengaruh terhadap pengendalian internal. Belum adanya konsistensi hasil pengujian empiris maka dapat dirumuskan hipotesis penelitian sebagai berikut: 


\section{H4: Sistem pengendalian internal berpengaruh positif dan signifikan terhadap akuntabilitas}

\section{METODE PENELITIAN}

\section{Jenis Penelitian}

Jenis penelitian ini dirancang sebagai penelitian kausal dengan pendekatan kuantitatif. Penelitian kausal berguna untuk mengukur hubungan antara variabel riset, atau untuk menganalisis pengaruh suatu variabel terhadap variabel lainnya. Peneliti menggunakan desain penelitian ini untuk memberikan bukti empiris dan menganalisis pengaruh kompetensi aparat, komitmen organisasi, partisipasi masyarakat dan sistem pengendalian internal terhadap akuntabilitas pengelolaan dana desa.

\section{Populasi dan Sampel}

Populasi yang digunakan dalam penelitian ini adalah seluruh masyarakat didesa/kampung di Kota Jayapura. Terdapat 14 Kampung di Kota Jayapura. Penelitian ini mengambil sampel secara purposive (purposive sampling) yaitu sampel diambil dengan beberapa kriteria tertentu dari populasi. Beberapa karakteristik dari sampel adalah sebagai berikut:

1) Merupakan aparat desa/kampung di 14 kampung dikota Jayapura

2) Telah menjabat sebagai aparat desa/kampung minimal 1 tahun

3) Merupakan pemuka/tokoh ataupun warga masyarakat kampung

\section{Jenis dan Sumber Data}

Jenis data yang digunakan dalam penelitian ini adalah data kuantitatif, yaitu merupakan data yang berbentuk skala likert. Penelitian ini menggunakan teknik survey dengan data primer berupa kuesioner.

\section{Variabel Penelitian dan Definisi Operasional Variabel}

1) Variabel Penelitian

Variabel dependen yang digunakan dalam penelitian ini adalah Akuntabilitas Pengelolaan Dana Desa $(\mathrm{Y})$. Sementara variabel independen $(\mathrm{X})$ dalam penelitian ini adalah 
Kompetensi Aparat, Komitmen Organisasi, Partisipasi Masyarakat, dan Sistem Pengendalian Internal.

Pengukuran variabel digambarkan dalam skala likert (likert scale). Skala likert ini menggunakan lima angka penilaian yaitu (1) Sangat Tidak Setuju, (2) Tidak Setuju, (3) Kurang Setuju, (4) Setuju, dan (5) Sangat Setuju.

\section{2) Definisi Operasional}

Adapun operasionalisasi variabel seperti terlihat pada Tabel 1 dibawah ini:

\section{Tabel 1}

\section{Operasionalisasi Variabel}

\begin{tabular}{|c|c|c|}
\hline KONSTRUK & DIMENSI & INDIKATOR \\
\hline \multirow{6}{*}{$\begin{array}{l}\text { Kompetensi Aparat } \\
\text { (X1) }\end{array}$} & \multirow{2}{*}{$\begin{array}{l}\text { Pengetahuan } \\
\text { (Knowledge) }\end{array}$} & Pengetahuan \\
\hline & & Kemampuan meningkatkan pengetahuan \\
\hline & \multirow{2}{*}{ Kemampuan (Skills) } & Keahlian Teknis \\
\hline & & Kemampuan mencari solusi \\
\hline & \multirow{2}{*}{ Sikap (Attitude) } & Inisiatif dalam bekerja \\
\hline & & Keramahan dan kesopanan \\
\hline \multirow{5}{*}{$\begin{array}{l}\text { Komitmen Organisasi } \\
\text { (X2) }\end{array}$} & \multirow[t]{2}{*}{ Afektif } & Keyakinan terhadap tujuan oranisasi \\
\hline & & Perasaan memiliki organisasi \\
\hline & \multirow[t]{2}{*}{ Keberlanjutan } & $\begin{array}{l}\text { Mempertahankan keanggotaan } \\
\text { organisasi }\end{array}$ \\
\hline & & Kesetiaan dalam organisasi \\
\hline & Normatif & $\begin{array}{l}\text { Kesediaan mengerahkan tenaga atas } \\
\text { nama organisasi }\end{array}$ \\
\hline \multirow{6}{*}{$\begin{array}{l}\text { Partisipasi Masyarakat } \\
\text { (X3) }\end{array}$} & $\begin{array}{l}\text { Pengambilan } \\
\text { Keputusan }\end{array}$ & $\begin{array}{l}\text { Keterlibatan dalam pengambilan } \\
\text { keputusan program-program desa }\end{array}$ \\
\hline & \multirow[b]{2}{*}{ Penyusunan Anggaran } & Mengusulkan rencana anggaran \\
\hline & & $\begin{array}{l}\text { Terlibat dalam rapat paripurna } \\
\text { (musrenbang) }\end{array}$ \\
\hline & \multirow{3}{*}{$\begin{array}{l}\text { Pelaksanaan } \\
\text { Anggaran }\end{array}$} & Terlibat mengawasi dan melaporkan \\
\hline & & $\begin{array}{l}\text { Memberikan penilaian pelaksanaan } \\
\text { anggaran }\end{array}$ \\
\hline & & Memberikan penghargaan \\
\hline \multirow{5}{*}{$\begin{array}{l}\text { Sistem Pengendalian } \\
\text { Internal (X4) }\end{array}$} & $\begin{array}{l}\text { Lingkungan } \\
\text { Pengendalian }\end{array}$ & $\begin{array}{l}\text { Pemeriksaan kelengkapan dokumen } \\
\text { pencatatan }\end{array}$ \\
\hline & Penilaian Resiko & Struktur Organisasi \\
\hline & $\begin{array}{l}\text { Kegiatan } \\
\text { Pengendalian }\end{array}$ & Pengamanan Aset \\
\hline & \multirow{2}{*}{$\begin{array}{l}\text { Informasi dan } \\
\text { Komunikasi }\end{array}$} & Otorisasi \\
\hline & & Komunikasi efektif \\
\hline
\end{tabular}




\begin{tabular}{|c|l|l|}
\hline KONSTRUK & \multicolumn{1}{|c|}{ DIMENSI } & \multicolumn{1}{c|}{ INDIKATOR } \\
\hline & Pemantauan & Tindak lanjut review/saran \\
\hline \multirow{4}{*}{ Akuntabilitas $(\mathrm{Y})$} & \multirow{2}{*}{ Kejujuran dan Hukum } & Kejujuran dan keterbukaan informasi \\
\cline { 2 - 3 } & \multirow{3}{*}{ Proses } & Kepatuhan dalam pelaporan \\
\cline { 2 - 3 } & & Kesesuaian prosedur \\
\cline { 3 - 3 } & & Kecukupan Informasi \\
\cline { 3 - 3 } & & Ketepatan Penyampaian Laporan \\
\hline
\end{tabular}

Sumber: Penulis, 2020

\section{Metode Analisis Data}

Pengujian hipotesis dalam penelitian ini adalah menggunakan Structural Equation Model (SEM) dengan metode Partial Least Square (PLS) dengan menggunakan software Warp Pls 6.0. PLS untuk menguji secara simultan hubungan antar konstruk laten dalam hubungan linear ataupun nonlinear dengan banyak indikator baik berbentuk reflektif, formatif dan MIMIC. Pengujian atas validasi dan reliabilitas dengan melakukan evaluasi model pengukuran atau Outer Model yaitu Covergent Validity, Discriminat Validity dan Composite Reliability. Goodness of fit pada inner model diukur menggunakan R square variabel laten dependen, $\mathrm{Q}$ square predictive relevance untuk model struktural yang digunakan untuk mengukur seberapa baik nilai observasi dihasilkan oleh model dan juga estimasi parameternya. Nilai $Q$ square> 0 menunjukkan model memiliki predictive relevance yang baik, sebaliknya jika nilai $Q$ square $\leq 0$ menunjukkan model kurang memiliki predictive relevance. Pengujian hipotesis dengan uji t pada inner model. 


\section{MODEL PENELITIAN}

\section{Gambar 1}

\section{Model Penelitian}

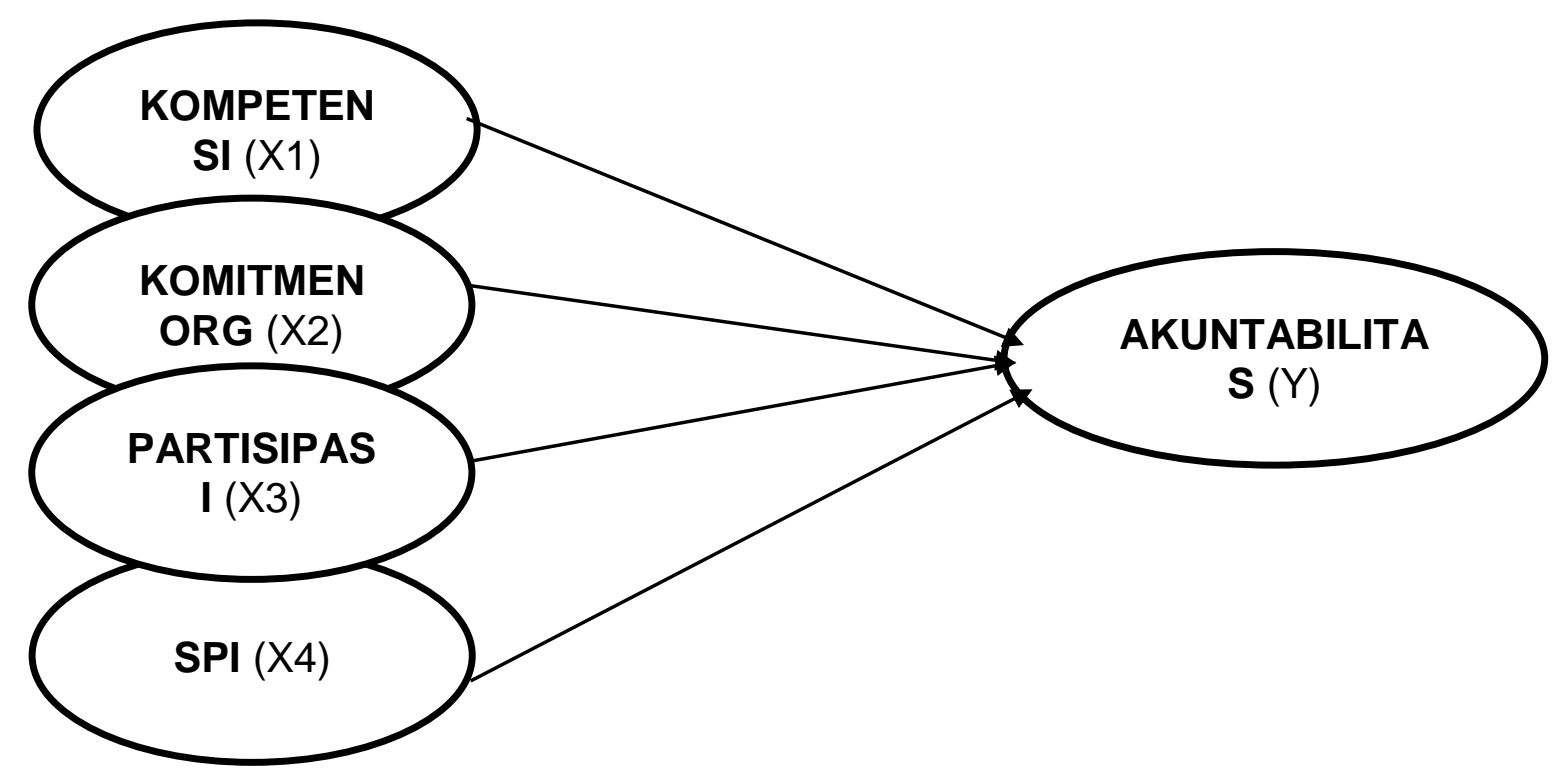

Sumber: Penulis, 2020

\section{HASIL PENELITIAN DAN PEMBAHASAN}

\section{Deskripsi Penelitian}

Pengumpulan data dilakukan dengan menyebarkan kuesioner penelitian ke 14 kampung yang ada di Kota Jayapura. Distribusi kuesioner seperti tampak pada Tabel 2 dibawah ini:

\section{Tabel 2}

\section{Lokasi dan Distribusi Kuesioner}

\begin{tabular}{|c|c|c|c|}
\hline No & Nama Distrik & Nama Kampung & \begin{tabular}{|c|} 
Jumlah \\
Kuesioner
\end{tabular} \\
\hline \multirow{3}{*}{1} & \multirow{3}{*}{ Abepura } & Nafri & 10 \\
\hline & & Enggros & 10 \\
\hline & & Koya Koso & 10 \\
\hline \multirow{2}{*}{2} & \multirow{2}{*}{ Jayapura Selatan } & Tobati & 10 \\
\hline & & Tahima Soroma & 10 \\
\hline 3 & Jayapura Utara & Kayo Batu & 10 \\
\hline \multirow{6}{*}{4} & \multirow{6}{*}{ Muara Tami } & Holtekam & 10 \\
\hline & & Skowyambe & 10 \\
\hline & & Skow Mabo & 10 \\
\hline & & Skow Sae & 10 \\
\hline & & Koya Tengah & 10 \\
\hline & & Kampung Mosso & 10 \\
\hline \multirow{2}{*}{5} & \multirow{2}{*}{ Heram } & Yoka & 10 \\
\hline & & Kampung Waena & 10 \\
\hline \multicolumn{3}{|c|}{ Total } & 140 \\
\hline
\end{tabular}

Sumber: Data Diolah, 2020 
Dari table diatas dapat dilihat bahwa kuesioner disebar ke 5 distrik yang memiliki kampung di Kota Jayapura yakni Distrik Abepura, Jayapura Selatan, Jayapura Utara, Heram dan Muara Tami. Terdapat 10 rangkap kuesioner yang disebar ke 14 kampung di Kota Jayapura. Jumlah kuesioner yang disebar yakni 140 rangkap.

Pada table 3 tentang distribusi dan pengembalian kuesioner dapat dilihat bahwa dari 140 kuesioner yang disebar terdapat 130 kuesioner yang kembali dan 125 kuesioner yang dapat diolah.

\section{Tabel 3}

\section{Distribusi dan Pengembalian Kuesioner}

\begin{tabular}{|r|l|r|r|}
\hline No & \multicolumn{1}{|c|}{ Keterangan } & Jumlah Kuesioner & \multicolumn{1}{|c|}{ Persentase } \\
\hline 1 & Distribusi Kuesioner & 140 & $100 \%$ \\
\hline 2 & Kuesioner yang Kembali & 130 & $93 \%$ \\
\hline 3 & Kuesioner yang tidak Kembali & 10 & $7 \%$ \\
\hline 4 & Kuesioner yang tidak dapat diolah & 5 & $4 \%$ \\
\hline 5 & Jumlah Kuesioner yang diolah & 125 & $96 \%$ \\
\hline
\end{tabular}
Sumber: Data Diolah, 2020

Karakteristik data responden dalam penelitian ini dapat dilihat pada Tabel 4 sebagai berikut: 
Tabel 4

Karakteristik Data Responden

\begin{tabular}{|c|c|c|c|}
\hline \multicolumn{2}{|c|}{ KARAKTERISTIK } & FREKUENSI & PERSENTASE \\
\hline \multirow{2}{*}{ JENIS KELAMIN } & LAKI-LAKI & 88 & $70 \%$ \\
\hline & PEREMPUAN & 37 & $30 \%$ \\
\hline \multirow{8}{*}{ UMUR } & $17-20$ & 2 & $2 \%$ \\
\hline & $21-30$ & 18 & $14 \%$ \\
\hline & $31-40$ & 30 & $24 \%$ \\
\hline & $41-50$ & 32 & $26 \%$ \\
\hline & $51-60$ & 27 & $22 \%$ \\
\hline & $61-70$ & 7 & $6 \%$ \\
\hline & $71-80$ & 1 & $1 \%$ \\
\hline & TANPA KETERANGAN & 8 & $6 \%$ \\
\hline \multirow{8}{*}{ TINGKAT PENDIDIKAN } & SD & 5 & $4 \%$ \\
\hline & SMP & 16 & $13 \%$ \\
\hline & SMA & 59 & $47 \%$ \\
\hline & D3 & 4 & $3 \%$ \\
\hline & S1 & 30 & $24 \%$ \\
\hline & $\mathrm{S} 2$ & 1 & $1 \%$ \\
\hline & LAINNYA & 7 & $6 \%$ \\
\hline & TANPA KETERANGAN & 3 & $2 \%$ \\
\hline \multirow{5}{*}{ MASA KERJA } & $<1$ TAHUN & 20 & $16 \%$ \\
\hline & 2 - 5 TAHUN & 62 & $50 \%$ \\
\hline & 6 - 10 TAHUN & 11 & $9 \%$ \\
\hline & $>10$ TAHUN & 15 & $12 \%$ \\
\hline & TANPA KETERANGAN & 17 & $14 \%$ \\
\hline \multirow{10}{*}{ JABATAN/POSISI } & KEPALA KAMPUNG & 6 & $5 \%$ \\
\hline & \begin{tabular}{|l|} 
SEKERTARIS \\
\end{tabular} & 8 & $6 \%$ \\
\hline & BENDAHARA & 4 & $3 \%$ \\
\hline & KAUR & 32 & $26 \%$ \\
\hline & KAUR KEUANGAN & 5 & $4 \%$ \\
\hline & \begin{tabular}{|l|} 
OPERATOR \\
\end{tabular} & 1 & $1 \%$ \\
\hline & BAMUSKAM & 17 & $14 \%$ \\
\hline & TOKOH MASYARAKAT & 35 & $28 \%$ \\
\hline & MASYARAKAT & 15 & $12 \%$ \\
\hline & PENDAMPING KAMPUNG & 2 & $2 \%$ \\
\hline
\end{tabular}

Sumber: Data Diolah, 2020

\section{Evaluasi Model Pengukuran atau Outer Model}

Terdapat 3 kriteria dalam teknik analisa data dengan Warp- PLS untuk menilai outer model yaitu Convergent Validity, Discriminant Validity dan Composite Reliability.

Tabel 5

Hasil Output Combined Loading dan Cross Loading

\begin{tabular}{|r|l|c|l|c|c|l|}
\hline \multirow{2}{*}{ No } & \multicolumn{1}{|c|}{ Variabel } & SE & Indikator & $\begin{array}{c}\text { Loading } \\
\text { Factor }\end{array}$ & $\begin{array}{c}\text { P } \\
\text { value }\end{array}$ & Keterangan \\
\hline \multirow{2}{*}{1} & Kompetensi & 0,077 & KAK1 & 0,597 & $<0,001$ & Valid \\
\cline { 2 - 7 } & Aparat & 0,075 & KAK2 & 0,719 & $<0,001$ & Valid \\
\cline { 2 - 7 } & 0,078 & KAK3 & 0,567 & $<0,001$ & Valid \\
\hline
\end{tabular}




\begin{tabular}{|c|c|c|c|c|c|c|}
\hline No & Variabel & SE & Indikator & $\begin{array}{l}\text { Loading } \\
\text { Factor }\end{array}$ & $\begin{array}{c}P \\
\text { value }\end{array}$ & Keterangan \\
\hline & & 0,075 & KAK4 & 0,722 & $<0,001$ & Valid \\
\hline & & 0,074 & KAK5 & 0,802 & $<0,001$ & Valid \\
\hline & & 0,074 & KAK6 & 0,800 & $<0,001$ & Valid \\
\hline \multirow{6}{*}{2} & \multirow{6}{*}{$\begin{array}{l}\text { Komitmen } \\
\text { Organisasi }\end{array}$} & 0,074 & KO1 & 0,764 & $<0,001$ & Valid \\
\hline & & 0,074 & $\mathrm{KO} 2$ & 0,787 & $<0,001$ & Valid \\
\hline & & 0,073 & $\mathrm{KO} 3$ & 0,825 & $<0,001$ & Valid \\
\hline & & 0,074 & $\mathrm{KO} 4$ & 0,805 & $<0,001$ & Valid \\
\hline & & 0,077 & $\mathrm{KO5}$ & 0,639 & $<0,001$ & Valid \\
\hline & & 0,081 & KO6 & 0,415 & $<0,001$ & Valid \\
\hline \multirow{6}{*}{3} & \multirow{6}{*}{$\begin{array}{l}\text { Partisipasi } \\
\text { Masyarakat }\end{array}$} & 0,076 & PM1 & 0,646 & $<0,001$ & Valid \\
\hline & & 0,074 & PM2 & 0,758 & $<0,001$ & Valid \\
\hline & & 0,075 & PM3 & 0,712 & $<0,001$ & Valid \\
\hline & & 0,076 & PM4 & 0,687 & $<0,001$ & Valid \\
\hline & & 0,076 & PM5 & 0,678 & $<0,001$ & Valid \\
\hline & & 0,080 & PM6 & 0,456 & $<0,001$ & Valid \\
\hline \multirow{9}{*}{4} & \multirow{9}{*}{ SPI } & 0,074 & SPI1 & 0,784 & $<0,001$ & Valid \\
\hline & & 0,074 & SPI2 & 0,799 & $<0,001$ & Valid \\
\hline & & 0,074 & SPI3 & 0,791 & $<0,001$ & Valid \\
\hline & & 0,073 & $\mathrm{SPI} 4$ & 0,820 & $<0,001$ & Valid \\
\hline & & 0,074 & SPI5 & 0,798 & $<0,001$ & Valid \\
\hline & & 0,073 & SPI6 & 0,822 & $<0,001$ & Valid \\
\hline & & 0,076 & SPI7 & 0,676 & $<0,001$ & Valid \\
\hline & & 0,074 & SPI8 & 0,774 & $<0,001$ & Valid \\
\hline & & 0,075 & SPI9 & 0,711 & $<0,001$ & Valid \\
\hline \multirow{5}{*}{5} & \multirow{5}{*}{ Akuntabilitas } & 0,072 & AKTB1 & 0,877 & $<0,001$ & Valid \\
\hline & & 0,072 & AKTB2 & 0,871 & $<0,001$ & Valid \\
\hline & & 0,073 & AKTB3 & 0,832 & $<0,001$ & Valid \\
\hline & & 0,073 & AKTB4 & 0,835 & $<0,001$ & Valid \\
\hline & & 0,074 & AKTB5 & 0,786 & $<0,001$ & Valid \\
\hline
\end{tabular}

Convergent Validity dari model pengukuran dapat dilihat dari korelasi antara skor indikator dengan skor konstruknya (loading factor) dengan kriteria nilai loading factor dari setiap indikator lebih besar dari 0,70 dapat dikatakan valid. Hulland (1999) dalam Wonar (2018) untuk tahap pengembangan kontruk dan skala pengukuran atau pengembangan instrument penelitian, nilai faktor loading $0.4-0.5$ dianggap cukup. Oleh karena itu, loading factor antara 0,40-0,70 harus tetap dipertahankan. Berdasarkan data pada table diatas maka 
dapat disimpulkan bahwa data Combined Loading and Cross-Lodings telah memenuhi kriteria.

\section{Hasil Output Latent Variabel Coefficient}

\begin{tabular}{|c|c|c|c|c|c|}
\hline & KAK & KO & PM & SPI & AKUNTAB \\
\hline R-squared & & & & & 0.705 \\
\hline Adj. R-squared & & & & & 0.696 \\
\hline Composite reliab. & 0.855 & 0.861 & 0.822 & 0.932 & 0.923 \\
\hline Cronbach's alpha & 0.795 & 0.803 & 0.738 & 0.917 & 0.896 \\
\hline Avg. var. extrac. & 0.500 & 0.518 & 0.440 & 0.603 & 0.707 \\
\hline Full collin. VIF & 1.556 & 1.718 & 1.413 & 2.368 & 2.467 \\
\hline Q-squared & & & & & 0.664 \\
\hline
\end{tabular}

Sumber: Data Diolah, 2020

Selanjutnya pengukuran dari Convergent validity adalah dengan melihat nilai AVE (Average Variance Extracted), bahwa AVE yang digunakan untuk evaluasi validitas konvergen, kriteria yang harus dipenuhi yaitu $A V E>0,50$. Berdasarkan data pada gambar diatas maka variable Kompetensi, Komitmen Organisasi, SPI dan Akuntabilitas telah memenuhi kriteria sedangkan variable Partisipasi Masyarakat belum memenuhi kriteria karena nilai $\mathrm{AVE}<0,50$.

\section{Discriminant Validity}

Discriminant validity dinilai dari cross-loading pengukuran dengan konstruk. dengan melihat loading konstruk laten yang akan memprediksi indikatornya/ dimensi lebih baik daripada konstruk lainnya. Jika korelasi konstruk dengan pokok pengukuran (setiap indikator) lebih besar daripada ukuran konstruk lainnya maka validitas diskriminan terpenuhi. Berdasarkan table dibawah ini maka dapat simpulkan bahwa korelasi konstruk dengan pokok pengukuran (setiap indikator) lebih besar daripada ukuran konstruk lainnya maka dapat disimpulkan bahwa validitas diskriminan terpenuhi. 
Tabel 6

Output Nilai Loading Konstruk Laten

\begin{tabular}{|c|c|c|c|c|c|c|c|}
\hline \multirow{2}{*}{ Indikator } & \multirow{2}{*}{ Loading } & \multicolumn{5}{|c|}{ Nilai Loading ke Konstruk Lainnya } & \multirow{2}{*}{ Keterangan } \\
\hline & & KAK & KO & \begin{tabular}{l|l}
$\mathbf{P M}$ \\
\end{tabular} & SPI & AKTB & \\
\hline KAK1 & 0,597 & & 0,391 & 0,04 & $-0,077$ & 0,076 & Memenuhi discriminant validity \\
\hline KAK2 & 0,719 & & $-0,254$ & 0,166 & 0,071 & $-0,146$ & Memenuhi discriminant validity \\
\hline KAK3 & 0,567 & & $-0,231$ & 0,244 & $-0,008$ & $-0,198$ & Memenuhi discriminant validity \\
\hline KAK4 & 0,722 & & 0,118 & 0,028 & 0,29 & $-0,152$ & Memenuhi discriminant validity \\
\hline KAK5 & 0,802 & & $-0,079$ & $-0,203$ & $-0,107$ & 0,201 & Memenuhi discriminant validity \\
\hline KAK6 & 0,800 & & 0,073 & $-0,173$ & $-0,156$ & 0,150 & Memenuhi discriminant validity \\
\hline KO1 & 0,764 & $-0,093$ & & $-0,111$ & 0,032 & 0,191 & Memenuhi discriminant validity \\
\hline $\mathrm{KO} 2$ & 0,787 & $-0,124$ & & $-0,097$ & $-0,047$ & 0,230 & Memenuhi discriminant validity \\
\hline KO3 & 0,825 & 0,066 & & $-0,039$ & $-0,014$ & $-0,111$ & Memenuhi discriminant validity \\
\hline KO4 & 0,805 & 0,105 & & 0,071 & 0,135 & $-0,163$ & Memenuhi discriminant validity \\
\hline KO5 & 0,639 & $-0,073$ & & 0,138 & 0,104 & $-0,275$ & Memenuhi discriminant validity \\
\hline KO6 & 0,415 & 0,184 & & 0,115 & $-0,362$ & 0,172 & Memenuhi discriminant validity \\
\hline PM1 & 0,646 & 0,325 & $-0,071$ & & 0,034 & 0,203 & Memenuhi discriminant validity \\
\hline PM2 & 0,758 & $-0,010$ & $-0,174$ & & 0,061 & 0,053 & Memenuhi discriminant validity \\
\hline PM3 & 0,712 & $-0,238$ & 0,082 & & 0,070 & 0,235 & Memenuhi discriminant validity \\
\hline PM4 & 0,687 & $-0,047$ & 0,234 & & $-0,052$ & $-0,103$ & Memenuhi discriminant validity \\
\hline PM5 & 0,678 & 0,071 & 0,021 & & $-0,024$ & $-0,269$ & Memenuhi discriminant validity \\
\hline PM6 & 0,456 & $-0,107$ & $-0,121$ & & $-0,143$ & $-0,186$ & Memenuhi discriminant validity \\
\hline SPI1 & 0,784 & 0,044 & 0,218 & $-0,085$ & & $-0,050$ & Memenuhi discriminant validity \\
\hline SPI2 & 0,799 & 0,056 & 0,115 & 0,036 & & $-0,250$ & Memenuhi discriminant validity \\
\hline SPI3 & 0,791 & 0,097 & $-0,066$ & $-0,055$ & & $-0,030$ & Memenuhi discriminant validity \\
\hline SPI4 & 0,820 & $-0,116$ & 0,003 & 0,062 & & $-0,012$ & Memenuhi discriminant validity \\
\hline SPI5 & 0,798 & $-0,081$ & 0,011 & $-0,050$ & & 0,134 & Memenuhi discriminant validity \\
\hline SPI6 & 0,822 & 0,023 & $-0,142$ & 0,008 & & $-0,001$ & Memenuhi discriminant validity \\
\hline SPI7 & 0,676 & 0,048 & $-0,051$ & 0,073 & & $-0,255$ & Memenuhi discriminant validity \\
\hline SPI8 & 0,774 & $-0,129$ & $-0,091$ & 0,018 & & 0,180 & Memenuhi discriminant validity \\
\hline SPI9 & 0,711 & 0,073 & 0,000 & 0,000 & & 0,28 & Memenuhi discriminant validity \\
\hline AKTB1 & 0,877 & 0,019 & $-0,035$ & 0,078 & 0,122 & & Memenuhi discriminant validity \\
\hline AKTB2 & 0,871 & 0,006 & $-0,144$ & 0,053 & 0,034 & & Memenuhi discriminant validity \\
\hline AKTB3 & 0,832 & $-0,051$ & 0,055 & 0,047 & $-0,137$ & & Memenuhi discriminant validity \\
\hline AKTB4 & 0,835 & 0,057 & $-0,131$ & $-0,046$ & $-0,142$ & & Memenuhi discriminant validity \\
\hline AKTB5 & 0,786 & $-0,033$ & 0,279 & $-0,147$ & 0,122 & & Memenuhi discriminant validity \\
\hline
\end{tabular}

Sumber: Data Diolah, 2020

\section{Composite Realibility}

Pengujian realibilitas konstruk yang dapat diukur dengan dua kriteria yaitu composite reliability dan cronbach's alpha. Composite Reliability data yang memiliki composite reliability $>0,8$ mempunyai reliabilitas yang tinggi. Average Variance Extracted (AVE) diharapkan $>0,5$ dan nilai cronbach's alpha dinyatakan reliabel diharapkan $>0,6$ untuk semua 
konstruk.. Berikut ini hasil dari output latent variable coefficients, ditunjukkan pada table dibawah ini:

Tabel 7

Composite Reliability dan Croncbach's Alpha

\begin{tabular}{|l|r|r|l|}
\hline \multicolumn{1}{|c|}{ Variabel } & Composite Reliability & Crocbach's Alpha & Keterangan \\
\hline Kompetensi Aparat Kampung & 0,855 & 0,795 & Reliabel \\
\hline Komitmen Organisasi & 0,861 & 0,803 & Reliabel \\
\hline Partisipasi Masyarakat & 0,822 & 0,738 & Reliabel \\
\hline Sistem Pengendalian Internal & 0,932 & 0,917 & Reliabel \\
\hline Akuntabilitas & 0,923 & 0,896 & Reliabel \\
\hline
\end{tabular}

Berdasarkan tabel diatas dapat disimpulkan bahwa semua konstruk memenuhi kriteria reliabel. Hal ini ditunjukkan dengan nilai composite reliability di atas 0,70 dan nilai Cronbach's alpha di atas 0.60 sebagaimana diatur oleh kriteria reliabilitas.

\section{Evaluasi Model Struktural atau Inner Model}

Pengujian berikut adalah melakukan evaluasi structural (Inner Model) yang meliputi uji kecocokan model (model fit) path coefficient dan $R^{2}$. Untuk menilai hasil suatu model dikatakan fit dalam program WarpPLS 6.0 dapat dilihat dari output general results. Terlihat pada model fit indices and $p$-value menampilkan hasil sepuluh indicator fit, yaitu:

a. Average path coefficient (APC) memiliki nilai $p<0,05$.

b. Average R-Squared (ARS) memiliki nilai $p<0,05$

C. Average Adjusted R-Squared (AARS) memiliki nilai $p<0,05$.

d. Average Block Variance Inflation (AVIF) memiliki nilai $<5$ dan idealnya 3,3.

e. Average full collinearity VIF (AFVIF) memiliki nilai $<5$ dan idealnya 3,3.

f. Tenenhaus GoF (GoF) memiliki nilai small $>=0,1$, medium $>=0,25$, large $>=0,36$.

g. Sympson's Paradox Ratio (SPR) memiliki nilai $>0,7$ dan idealnya 1.

h. R-Squared Contribution Ratio (RSCR) memiliki nilai >=0,9 dan idealnya 1.

i. Statistical Suppression Ratio (SSR) diterima jika nilai $>0,7$.

j. Nonlinear Bivariate Causality Direction Ratio (NLBCDR) diterima jika nilai $>=0,7$. 


\section{Tabel 8}

\section{Model Fit dan Quality Indices}

\begin{tabular}{|l|r|r|l|l|}
\hline \multicolumn{1}{|c|}{ Model Fit dan Quality Indices } & \multicolumn{1}{c|}{ Index } & \multicolumn{1}{c|}{ P Value } & \multicolumn{1}{|c|}{ Krite ria } & \multicolumn{1}{|c|}{ Keterangan } \\
\hline Average path coefficient (APC) & 0,276 & $<0,001$ & $\mathrm{P}<0.05$ & Diterima \\
\hline Average R-Squared (ARS) & 0,705 & $<0,001$ & $\mathrm{P}<0.05$ & Diterima \\
\hline Average Adjusted R-Squared & 0,696 & $<0,001$ & $\mathrm{P}<0.05$ & Diterima \\
\hline Average Block Variance Inflation Factor (AVIF) & 1,481 & $\leq 5$ dan idealnya $\leq 3,3$ & Diterima \\
\hline Average Full Collonearity VIF (AFVIF) & 1,904 & $\leq 5$ dan idealnya $\leq 3,3$ & Diterima \\
\hline & & small $\geq 0,1$, medium & \\
Tenenhaus GoF (GoF) & 0,625 & $\geq 0,25$, large $\geq 0,36$ & Large \\
\hline Sympson's paradox ratio (SPR) & 1,000 & $\geq 0,7$ dan idealnya $=1$ & Diterima \\
\hline R-Squared Contribution Ratio (RSCR) & 1,000 & $\geq 0,9$ dan idealnya $=1$ & Diterima \\
\hline Statictical Suppression Ratio (SSR) & 1,000 & \multicolumn{2}{|c|}{$\geq 0,7$} & Diterima \\
\hline Nonlinear Bivariate Causality Direction Ratio (NLBCDR) & 1,000 & \multicolumn{2}{|c|}{$\geq 0,7$} & Diterima \\
\hline
\end{tabular}

Sumber: Data Diolah, 2020

Berdasarkan tabel di atas nilai yang diperoleh dari sepuluh kriteria sudah terpenuhi, sehingga dapat dikatakan model tersebut telah memenuhi prasyarat model fit dan inner model dapat diterima.

\section{Measurement Model}

\section{Gambar 4 \\ Measurement Model}

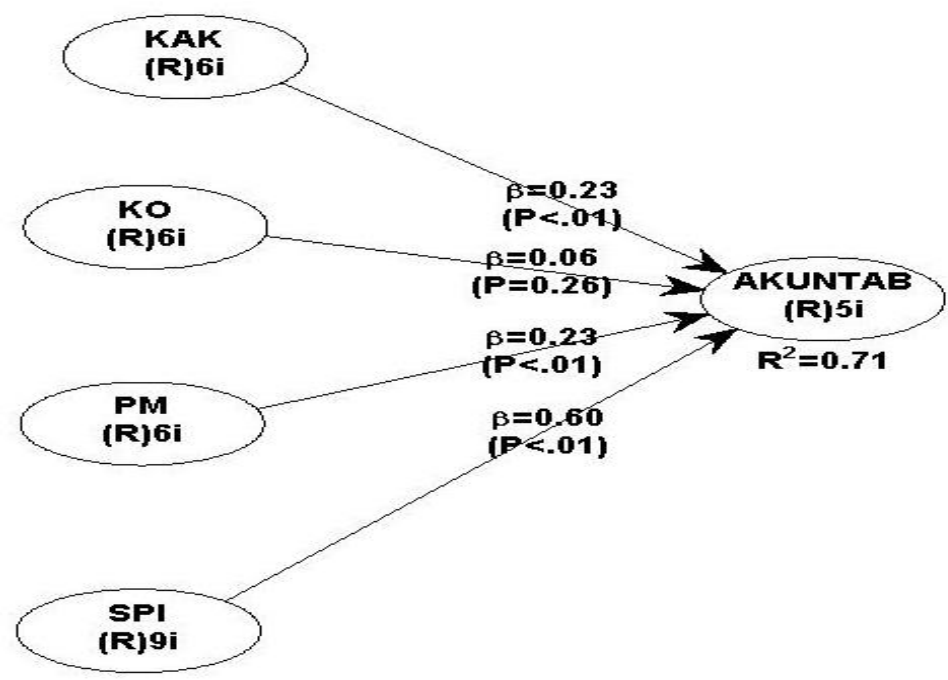

Sumber: Data Diolah, 2020 
Berdasarkan hasil pengujian Nilai path coefficient pengaruh kompetensi aparat terhadap akuntabilitas sebesar 0,23 , pengaruh komitmen organisasi terhadap akuntabilitas sebesar 0,06, pengaruh partisipasi masyarakat terhadap akuntabilitas sebesar 0,23 dan pengaruh SPI terhadap akuntabilitas sebesar 0,60 .

Structural Equation Model untuk Pengaruh Kompetensi, Komitmen Organisasi, Partisipasi Masyarakat dan Sistem Pengendalian Internal terhadap Akuntabilitas Pengelolaan Dana Desa/Kampung adalah sebagai berikut:

$$
\eta=0.23 \xi 1+0.06 \xi 2+0.23 \xi 3+0.60 \xi 4
$$

Tabel 9

Hasil Uji R Square

\begin{tabular}{|l|r|}
\hline & R Square \\
\hline $\begin{array}{l}\text { Akuntabilitas pengelolaan dana } \\
\text { kampung }\end{array}$ & 0,71 \\
\hline
\end{tabular}

Sumber: Data Diolah, 2020

Dari table diatas diketahui bahwa model pengujian yang diujikan dalam penelitian ini yaitu kompetensi aparat, komitmen organisasi, partisipasi masyarakat dan sistem pengendalian internal mempengaruhi akuntabilitas pengelolaan dana desa/kampung sebesar $71 \%$ dan sisanya yaitu $29 \%$ dipengaruhi oleh variable lain yang tidak diteliti didalam penelitian ini.

\section{Pembahasan Hasil Pengujian Hipotesis}

Pengujian hipotesis bertujuan untuk membuktikan kebenaran dugaan awal penelitian atau hipotesis. Hasil korelasi antar konstruk diukur dengan melihat path coefficients dan tingkat signifikansinya. Tingkat signifikansi dalam penelitian ini adalah sebesar $5 \%$. Berikut ini merupakan data output path coefficients dan $\mathrm{P}$ Values yang diperoleh dari pengolahan data, dengan menguji pengaruh langsung atau direct effect dapat dilihat pada tabel dibawah ini : 
Tabel 10

Hasil Output Path Coefficient Model Direct Effect

\begin{tabular}{|l|r|r|l|}
\hline \multicolumn{1}{|c|}{ Variabel } & \multicolumn{1}{c|}{$\begin{array}{c}\text { Path } \\
\text { Coefficient }\end{array}$} & $\begin{array}{c}\text { P } \\
\text { Value }\end{array}$ & Keterangan \\
\hline KAK $>$ AKUNTABILITAS & 0,225 & 0,004 & Diterima \\
\hline KO-> AKUNTABILITAS & 0,056 & 0,262 & Ditolak \\
\hline PM $->$ AKUNTABILITAS & 0,226 & 0,004 & Diterima \\
\hline SPI $->$ AKUNTABILITAS & 0,597 & $<0,001$ & Diterima \\
\hline
\end{tabular}

Sumber: Data Diolah, 2020

\section{Uji Hipotesis 1 (H1) Pengaruh Kompetensi Aparat Desa/Kampung terhadap Akuntabilitas Pengelolaan Dana Desa/Kampung}

Pengujian hipotesis 1 (H1) yang menyatakan bahwa kompetensi aparatur desa/kampung memiliki pengaruh positif dan signifikan terhadap akuntabilitas dapat diterima dan terbukti benar dimana hasilnya dibuktikan dari hasil Output Path Coefficients and $P$ values yang menggambarkan penyajian hasil estimasi koefisien jalur (path coefficient) dan nilai p. Dari hasil pengujian diatas, terlihat nilai Path coefficients pengaruh kompetensi aparatur desa terhadap akuntabilitas adalah sebesar 0,225 dan signifikan pada 0,004 lebih kecil dari $p<0,05$ atau $5 \%$, sehingga hipotesis yang diajukan diterima.

Hasil pengujian menunjukkan bahwa semakin baik kompetensi aparat desa/kampung maka semakin baik juga tingkat akuntabilitas pengelolaan dana kampung. Teori stewardship (Davis et. al., 1997) dalam Mada et. al (2017) menekankan pada peranan steward selaku pengelola yang dipercaya mengelola sumber daya. Dalam penelitian ini steward/pengelola/manajemen merupakan aparat kampung yang semakin baik kompetensinya maka akan meningkatkan kinerjanya dengan meningkatkan akuntabilitas pengelolaan dana desa/kampung. Hasil penelitian ini didukung oleh penelitian terdahulu bahwa kompetensi berpengaruh terhadap akuntabilitas (Mada et. al., 2017; Aziiz \& Prastiti (2019); Umaira \& Adnan, 2019; Hendariz \& Siraz, 2020; Hardiningsih et.al., 2020; Apriana et. al., 2020). 


\section{Uji Hipotesis 2 (H2) Pengaruh Komitmen Organisasi terhadap Akuntabilitas Pengelolaan Dana Desa/Kampung}

Pengujian hipotesis $2(\mathrm{H} 2)$ yang menyatakan bahwa komitmen organisasi memiliki pengaruh positif dan signifikan terhadap akuntabilitas tidak dapat diterima dimana hasilnya dibuktikan dari hasil Output Path Coefficients and $\mathrm{P}$ values yang menggambarkan penyajian hasil estimasi koefisien jalur (path coefficient) dan nilai p. Dari hasil pengujian diatas, terlihat nilai Path coefficients pengaruh komitmen organisasi terhadap akuntabilitas adalah sebesar 0,056 dengan nilai signifikansi yaitu 0,262 atau lebih besar dari $p<0,05$ atau $5 \%$, sehingga hipotesis yang diajukan ditolak. Hasil penelitian ini berlawanan dengan mayoritas hasil penelitian yang menemukan bahwa komitmen organisasi berpengaruh terhadap akuntabilitas pengelolaan dana desa. (Mada et. al.,2017); Hardiningsih et.al., 2020; Apriana et. al., 2020). Sedangkan penelitian Nurkhasanah (2019) juga tidak menemukan adanya pengaruh antara komitmen organisasi dengan akuntabilitas. Hal ini mungkin disebabkan adanya faktor lain seperti pendampingan dari pendamping desa yang memang bertugas memfasilitasi jalannya organisasi termasuk peningkatan upaya menjadikan pemerintahan kampung yang akuntabel. Inspektorat Kota Jayapura melalui situs http://inspektorat.jayapurakota.go.id/berita/catatankritis-akhir-tahun-2019-tentang-pengelolaan-dana-kampung-di-kota-jayapura menguraikan sejumlah temuan kelemahan pengelolaan dana desa/kampung di Kota Jayapura termasuk rendahnya kompetensi aparat dan ketergantungan terhadap fungsi pendamping desa yang juga minim jumlahnya.

\section{Uji Hipotesis 3 (H3) Pengaruh Partisipasi Masyarakat terhadap Akuntabilitas Pengelolaan Dana Desa/Kampung}

Pengujian hipotesis $3(\mathrm{H} 3)$ yang menyatakan bahwa partisipasi masyarakat memiliki pengaruh positif dan signifikan terhadap akuntabilitas dapat diterima dan terbukti benar dimana hasilnya dibuktikan dari hasil Output Path Coefficients and $P$ values yang menggambarkan penyajian hasil estimasi koefisien jalur (path coefficient) dan nilai p. Dari hasil pengujian diatas, terlihat nilai Path coefficients pengaruh partisipasi masyarakat 
terhadap akuntabilitas adalah sebesar 0,226 dan signifikan pada 0,004 lebih kecil dari $\mathrm{p}<0,05$ atau $5 \%$, sehingga hipotesis yang diajukan diterima.

Hasil pengujian penelitian ini sejalan dengan penelitian lain yang menguji secara empiris pengaruh partisipasi masyarakat terhadap akuntabilitas (Sugista, 2017; Nurkhasanah 2019, Andriani 2019; Umaira \& Adnan, 2019; dan Astuti, 2019). Partisipasi masyarakat yang aktif meningkatkan akuntabilitas pengelolaan dana desa/kampung baik dari tahapan perencanaan yaitu saat pelaksanaan MUSREMBANG sehingga masyarakat mengetahui kegiatan dan program pemerintah kampung dan dapat mengawal proses mulai dari penetapan APBKampung sampai dengan pelaporan dan pengawasan pengelolaan dananya (Mada et. al, 2017; Sugista, 2017; Andriani, 2019; Astuti, 2019).

\section{Uji Hipotesis 4 (H4) Pengaruh Sistem Pengendalian Internal terhadap Akuntabilitas Pengelolaan Dana Desa/Kampung}

Pengujian hipotesis $4(\mathrm{H} 4)$ yang menyatakan bahwa sistem pengendalian internal memiliki pengaruh positif dan signifikan terhadap akuntabilitas dapat diterima dan terbukti benar dimana hasilnya dibuktikan dari hasil Output Path Coefficients and $\mathrm{P}$ values yang menggambarkan penyajian hasil estimasi koefisien jalur (path coefficient) dan nilai p. Dari hasil pengujian diatas, terlihat nilai Path coefficients pengaruh sistem pengendalian internal terhadap akuntabilitas adalah sebesar 0,597 dan signifikan pada $<0,001$ lebih kecil dari $\mathrm{p}<0,05$ atau $5 \%$, sehingga hipotesis yang diajukan diterima.

Hasil pengujian dalam penelitian ini membuktikan adanya pengaruh sistem pengendalian internal terhadap akuntabilitas pengelolaan dana kampung. Hasil ini didukung oleh penelitian terdahulu (Widyatama et. al., 2017; Aziiz \& Prastiti 2019; Hardiningsih et. al., 2020; Hendariz \& Siraz, 2020). Hal ini menunjukkan bahwa semakin baik sistem pengendalian internal semakin meningkatkan akuntabilitas. Dalam theory stewardship, manajemen akan berusaha agar dapat mengelola sumber daya yang dipercayakan dengan menerapkan sistem kerja yang terpercaya sehingga dapat memastikan tercapainya tujuan organisasi dan memperoleh kepercayaan masyarakat. 


\section{SIMPULAN}

Berdasarkan uraian diatas maka dapat disimpulkan sebagai berikut:

1) Terdapat pengaruh kompetensi aparat terhadap akuntabilitas pengelolaan dana kampung di Kota Jayapura

2) Tidak terdapat pengaruh komitmen organisasi terhadap akuntabilitas pengelolaan dana kampung di Kota Jayapura

3) Terdapat pengaruh partisipasi masyarakat terhadap akuntabilitas pengelolaan dana kampung di Kota Jayapura

4) Terdapat pengaruh sistem pengendalian internal aparat terhadap akuntabilitas pengelolaan dana kampung di Kota Jayapura

Kontribusi penelitian ini yaitu bahwa variable penelitian ini yaitu kompetensi aparat desa/kampung, partisipasi masyarakat dan sistem pengendalian internal yang baik dapat meningkatkan akuntabilitas pengelolaan dana desa/kampung. Pemerintah perlu melakukan intervensi berupa kegiatan pendampingan agar faktor-faktor penentu akuntabilitas ini dapat ditingkatkan sehingga pengelolaan dana desa/kampung semakin baik.

Saran bagi penelitian dimasa yang datang dapat juga menambah faktor-faktor lain sebagai variable penelitian dalam menganalisis peningkatan akuntabilitas pengelolaan dana desa/kampung seperti penggunaan teknologi infomasi, pemantauan dan sebagainya.

\section{DAFTAR PUSTAKA}

Andriani, M. (2019). Pengaruh Transparansi, Akuntabilitas, dan Partisipasi Masyarakat terhadap Pengelolaan Dana Desa (Studi Pada Desa Luk, Kecamatan Rhee, Kabupaten Sumbawa). E-Journal Akuntansi FEB Universitas Teknologi Sumbawa.

Apriana, S., Said, D., \& Nurleni, N. (2020). The Influence of Organizational Commitment, Competence of Village Fund Management Offficers, and Utilization of Information Technology on Accountability of Village. AFEBI Accounting Review, 4(02), 94-105.

Arifiyanto, D.F., Kurrohman, T. (2014). "Akuntabilitas Pengelolaan Alokasi Dana Desa di Kabupaten Jember". Jurnal Riset Akuntansi dan Keuangan, Vol (2) Nomor (3) Hal. 473485. 
Astuti, T. Y. (2019). Pengaruh penyajian laporan keuangan, aksesibilitas informasi desa dan partisipasi masyarakat terhadap akuntabilitas pengelolaan keuangan desa: studi kasus di Desa Danasari, Kecamatan Pemalang, Kabupaten Pemalang (Doctoral dissertation, UIN Walisongo).

Aziiz, M. N., \& Prastiti, S. D. (2019). Faktor-Faktor Yang Mempengaruhi Akuntabilitas Dana Desa. Jurnal Akuntansi Aktual, 334.

Donaldson, L., \& Davis, J. H. (1991). Stewardship theory or agency theory: CEO governance and shareholder returns. Australian Journal of management, 16(1), 49-64.

HARDININGSIH, P., Udin, U. D. I. N., MASDJOJO, G. N., \& SRIMINDARTI, C. (2020). Does Competency, Commitment, and Internal Control Influence Accountability?. The Journal of Asian Finance, Economics, and Business, 7(4), 223-233.

Hendaris, R. B., \& Siraz, R. (2020). ANALYSIS OF FACTORS INFLUENCING THE ACCOUNTABILITY OF VILLAGE FUNDS MANAGEMENT. Dinasti International Journal of Education Management And Social Science, 1(3), 400-411.

Indrianasari, N. T. (2017)."Peran Perangkat Desa dalam Akuntabilitas Pengelolaan Keuangan Desa (Studi pada Desa Karangsari Kecamatan Sukodono)". Jurnal IImiah IImu Akuntansi, Keuangan dan Pajak, vol. (1), no (2).

Kementerian Desa, Pembangunan Daerah Tertinggal, dan Transmigrasi. 2015. Indeks Desa Membangun 2015. Jakarta: Kementerian Desa, Pembangunan Daerah Tertinggal, dan Transmigrasi.

Mada, S., Kalangi, L., Gamaliel, H. (2017). "Pengaruh Kompetensi Aparat Pengelola Dana Desa, Komitmen Organisasi Pemerintah Desa, dan Partisipasi Masyarakat Terhadap Akuntabilitas Pengelolaan Dana Desa Di Kabupaten Gorontalo". Jurnal Riset Akuntansi.

Mulgan, R. (2000). "Comparing Accountability in the Public and Private Sector". National Council of The Institute of Public Administration, Australia.

Nurkhasanah, I. (2019). PENGARUH KOMPETENSI SUMBER DAYA MANUSIA, PEMANFAATAN TEKNOLOGI INFORMASI, PARTISIPASI PENGANGGARAN, PENGAWASAN, DAN KOMITMEN ORGANISASI PEMERINTAH DESA TERHADAP AKUNTABILITAS PENGELOLAAN DANA DESA(Doctoral dissertation, Skripsi, Universitas Muhammadiyah Magelang).

Peraturan Pemerintah No. 60 Tahun 2008 tentang Sistem Pengendalian Intern Pemerintah.

Peraturan Menteri Dalam Negeri Republik Indonesia Nomor 113 Tahun 2014 tentang Pengelolaan Keuangan Desa.

Peraturan Menteri Dalam Negeri Nomor 20 tahun 2018 tentang Pengelolaan Keuangan Desa

Peraturan Menteri Desa, Pembangunan Daerah Tertinggal, Dan Transmigrasi Republik Indonesia Nomor 16 Tahun 2018 Tentang Prioritas Penggunaan Dana Desa Tahun 2019

Riyanto, T. (2015). Akuntabilitas Finansial Dalam Pengelolaan Alokasi Dana Desa (Add) di Kantor Desa Perangat Selatan Kecamatan Marangkayu Kabupaten Kutai Kartanegara. Ejournal Administrasi Negara, 3(1), 199-130. 
Rulyanti, D., Sularso, R.A., Sayekti, Y. (2017). "Faktor-Faktor Yang Mempengaruhi Kinerja Pemerintah Desa Melalui Pengelolaan Keuangan Desa Sebagai Variabel Intervening".Jurnal Bisnis dan Managemen. Vol. (11), No (3). Hal 323-335.

Sugista, R. A. (2017). Pengaruh Transparansi, Akuntabilitas, dan Partisipasi Masyarakat dalam Pengelolaan Keuangan Desa terhadap Pembangunan Desa.

Tarjo, T. (2019). Pengaruh Kompetensi Aparat Desa dan Komitmen Organisasi Terhadap Akuntabilitas Dana Desa. Jurnal IImiah Tata Sejuta STIA Mataram, 5(2), 25-41.

Triyono., Achyani, F., \& Arfianyah, M.A. (2019). "The Determinant Accountability of Village Funds Management (Study in the Villages in Wonogiri District)". Jurnal Riset Akuntansi dan Keuangan Indonesia", Vol. (4), No. (2).

Umaira, S., \& Adnan, A. (2019). PENGARUH PARTISIPASI MASYARAKAT, KOMPETENSI SUMBER DAYA MANUSIA, DAN PENGAWASAN TERHADAP AKUNTABILITAS PENGELOLAAN DANA DESA (STUDI KASUS PADA KABUPATEN ACEH BARAT DAYA). Jurnal IImiah Mahasiswa Ekonomi Akuntansi, 4(3), 471-481.

Undang-undang Republik Indonesia Nomor 6 Tahun 2014 tentang Desa.

Widyatama, A., Novita, L., Dierespati. (2017)."Pengaruh Kompetensi dan Sistem Pengendalian

Internal Terhadap Akuntabilitas Pemerintah Desa dalam Mengelola Alokasi Dana Desa $(A D D) "$.

Akuntansi dan Keuangan Indonesia, Vol. 2, Nomor 2. 